REVISTA DE LA SEECI.

Febres-Cordero, Laura (2009): EL huidizo sentido de la independencia en la isla de Róbinson de Arturo Pietri. No 19. Julio. Año XIII. Páginas: 58 - 77

ISSN: 1576-3420 DOI: http://dx.doi.org/10.15198/seeci.2009.19.58-77

\title{
EL HUIDIZO SENTIDO DE LA INDEPENDENCIA EN LA ISLA DE RÓBINSON DE ARTURO USLAR PIETRI
}

\section{THE FUGITIVE SENSE OF THE INDEPENDENCE IN THE ROBINSON ISLAND OF ARTURO USLAR PIETRI}

\section{AUTORA \\ Laura Febres-Cordero. \\ Universidad Metropolitana de Caracas (Venezuela). \\ Lfebres@unimet.edu.ve}

\section{RESUMEN}

La isla de Róbinson de Arturo Uslar Pietri es, desde nuestro punto de vista, una de las obras más logradas, dentro de la producción de este venezolano quien nace en Caracas en 1901 y muere en 2006.

En este trabajo trataremos tres rasgos importantes de la producción Uslariana que resaltan dentro de esta novela histórica, los cuales se engloban en la urgencia que existe en el autor de convertir el lápiz en pincel del pensamiento. El primero de ellos será tratar a la Isla de Róbinson como novela histórica, el segundo, su pertenencia también a otra rama literaria muy conocida, como es la literatura de viajes y la tercera, la relación de la escritura con la realidad y el pensamiento; problemática que subyace a través de todo el texto. Esta novela histórica narra uno de los períodos más importantes en la historia de Venezuela y de Latinoamérica, su Independencia. El narrador escoge el momento en que ella rompe los límites del territorio de Venezuela para convertirse en 
REVISTA DE LA SEECI.

Febres-Cordero, Laura (2009): EL huidizo sentido de la independencia en la isla de Róbinson de Arturo Pietri. No 19. Julio. Año XIII. Páginas: 58 - 77

ISSN: 1576-3420 DOI: http://dx.doi.org/10.15198/seeci.2009.19.58-77

un suceso Latinoamericano y mundial. La obra es una reflexión sobre el sentido que tuvo este acontecimiento para los latinoamericanos, principalmente a través del pensamiento de uno de sus más grande ideólogos, Simón Rodríguez.

\section{PALABRAS CLAVE}

Novela histórica - Independencia - Pensamiento Latinoamericano - Libro de viajes.

\section{ABSTRACT}

The Arturo Uslar Pietri's Robinson's Island is, from our point of view, one of the most successful works, inside the production of this Venezuelan who is born in Caracas in 1901 and dies in 2006. In this work we will treat three important features of the production Uslariana that stand out inside this historical novel, which are included in the urgency that exists in the author of turning the pencil into paintbrush of the thought. The first one of them will be to treat to Robinson's Island as historical novel, the second one, his belonging also to another literary very known branch, since it is the literature of trips and the third one, the relation of the writing with the reality and the thought; problematics that sublies across the whole text. This historical novel narrates one of the most important periods. The narrator chooses the moment in which she breaks the limits of the territory of Venezuela to turn into a Latin-American and world event. The work is a reflection on the sense that had this event for the Latin Americans, principally across the thought of one of his bigger ideologists, Simón Rodríguez.

\section{KEY WORDS}

Historical novel - Independence - Latin-American thought - I free of trips. 


\section{REVISTA DE LA SEECI.}

Febres-Cordero, Laura (2009): EL huidizo sentido de la independencia en la isla

de Róbinson de Arturo Pietri. No 19. Julio. Año XIII. Páginas: 58 - 77

ISSN: 1576-3420 DOI: http://dx.doi.org/10.15198/seeci.2009.19.58-77

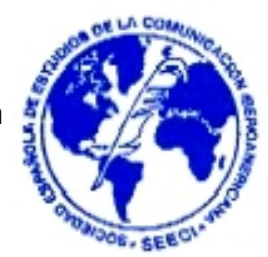

\section{ÍNDICE}

1. Introducción

2. La novela histórica y la Independencia.

3. El libro de viajes

4. La escritura en La Isla de Róbinson

5. Bibliografía

\section{Introducción}

"Leer es resucitar ideas sepultadas en el papel: cada palabra es un epitafio: llamarlas a la vida es

una especie de milagro, y para hacerlo es menester conocer los espiritus de las difuntas o tener espíritus equivalentes que subrogarles: un cuerpo con el alma de otro sería un disfraz de carnaval; y cuerpo sin alma, sería un cadáver."

Simón Rodríguez.

La isla de Róbinson de Arturo Uslar Pietri es, desde nuestro punto de vista, una de las obras más logradas, dentro de la producción de este venezolano quien nace en Caracas en 1901, vive una vida llena de ricas experiencias, tanto en el campo de la literatura como en el de la acción política y muere en el 2006.

Esta afirmación sobre la novela ha sido confirmada por Alexis Márquez Rodríguez, cuando dice: 
REVISTA DE LA SEECI.

Febres-Cordero, Laura (2009): EL huidizo sentido de la independencia en la isla de Róbinson de Arturo Pietri. No 19. Julio. Año XIII. Páginas: 58 - 77

ISSN: 1576-3420 DOI: http://dx.doi.org/10.15198/seeci.2009.19.58-77

"La isla de Róbinson es la mejor lograda de las novelas de Uslar Pietri. La más madura, la más acabada, la mejor concebida y realizada. En ella se combinan mejor que en todas las demás, por una parte la precisión y el enfoque temático y anecdótico, y por la otra un acopio de recursos técnicos y de lenguaje de una extraordinaria riqueza. Todo lo cual se estructura sabiamente y con una alta calidad estética, para formar un corpus relatístico en verdad excepcional." (Márquez Rodríguez, 1986, pág. 23)

En el campo político Arturo Uslar Pietri desempeñó muchas funciones, entre ellas podemos mencionar la de Ministro de Educación (1939-1940), Secretario de la Presidencia (1941-1943), Senador del Congreso de la República (1959-1963) y llegó a participar en las elecciones de 1963 para optar por la Presidencia de la República de Venezuela, pero fue derrotado.

Los géneros literarios no encasillaron su producción, los ejerció todos: poesía, teatro, ensayo, novela y cuento. Y no sólo esto, fue un maestro del artículo periodístico. Publicó un libro famoso de viajes El globo de colores y varios estudios sobre artistas plásticos como Giotto y Leonardo de Vinci. Su primera novela histórica Las Lanzas Coloradas (1930) escrita en París, cuando disfrutaba de la compañía de Miguel Ángel Asturias y Alejo Carpentier, ha sido traducida hoy a muchos idiomas.

En este trabajo trataremos tres rasgos importantes de la producción Uslariana que resaltan dentro de esta novela histórica, los cuales se engloban en la urgencia que existe en el autor de convertir el lápiz en pincel del pensamiento. El primero de ellos será tratar a la Isla de Róbinson como novela histórica, el segundo, su pertenencia también a otra rama literaria muy conocida como es la literatura de viajes y la tercera, 
REVISTA DE LA SEECI.

Febres-Cordero, Laura (2009): EL huidizo sentido de la independencia en la isla

de Róbinson de Arturo Pietri. No 19. Julio. Año XIII. Páginas: 58 - 77

ISSN: 1576-3420 DOI: http://dx.doi.org/10.15198/seeci.2009.19.58-77

la relación de la escritura con la realidad y el pensamiento; problemática que subyace a través de todo el texto.

Las aristas de estos tres problemas confluyen en uno solo, la creación de la novela. Ninguno de ellos es tan rígido como una cárcel, como tampoco es firme la identidad para el personaje principal, quien se inicia como Simón Rodríguez, cambia su nombre al de Samuel Róbinson y nuevamente termina llamándose Simón Rodríguez. Esto viene relacionado con su condición de hijo expósito, a quien ni su padre ni su madre confirieron una identidad. Lo mismo sucede, parcialmente, con otros personajes importantes de las novelas de Arturo Uslar Pietri, Fernando e Inés Fonta en las Lanzas Coloradas, que a pesar de tener padre legítimo no poseen conexión afectiva con él y Don J uan de Austria, el hijo bastardo de Felipe II, quien pasa sus primeros años de vida sin conocer a su padre y sin saber su verdadera identidad. Uslar Pietri parece sentirse fascinado por estos personajes, que están muy cerca de definir al sujeto latinoamericano, que en su gran mayoría carece de representación de la figura paterna.

La instancia paterna, cuya función esencial es la de estatuir y promover la ley, no cumple ni puede cumplir aquí su misión porque se desmorona de su posición en el significante Ser hijo de significa que el individuo, en cuanto sujeto humano, está capturado en un red de relaciones que lo preceden y condicionan su manera de percibirse y de aprehender el mundo. Sin punto de apoyo estabilizador, Fernando (al igual que Simón Rodríguez en esta novela) se va a la deriva, en busca de un asidero inalcanzable. El árbol que no puede echar raíces muere. La existencia privada del arraigamiento paterno ve truncadas sus posibilidades de ser. (López, 2002, pág. 658)

La novela trata diversas problemáticas que, como vasos comunicantes, amalgaman las experiencias del personaje principal con las del autor y a su vez, las de otros muchos 
REVISTA DE LA SEECI.

Febres-Cordero, Laura (2009): EL huidizo sentido de la independencia en la isla de Róbinson de Arturo Pietri. No 19. Julio. Año XIII. Páginas: 58 - 77

ISSN: 1576-3420 DOI: http://dx.doi.org/10.15198/seeci.2009.19.58-77

hombres con las cuales éstas se funden. Serán reveladas, entonces, en la escritura sus voces como lo más preciado durante el viaje que se describe; lo único que queda después del naufragio.

Eran infinitas voces de una legión de hombres. Pero siempre era la suya. Hasta aquella de ahora con que llamaba a Cocho, entre el ruido del mar. Voz de viejo, cascada, seca, tosida. No te sientes allí. No sobre la caja de papeles, no sobre aquel rescoldo de incendio, no sobre aquel eco de lo más viviente de todo lo que él había vivido. (Uslar, 1981, pág. 183)

\section{La novela histórica y la Independencia}

La obra puede ser considerada como novela histórica porque narra uno de los períodos más importantes en la historia de Venezuela y Latinoamérica, su Independencia. ${ }^{1}$ Pero no se habla solamente en ella de este período histórico sino también de aquellos precursores que contribuyeron con sus pensamientos y acciones a realizar el sueño de una América libre y productiva. En el ensayo magistral Godos, insurgentes y visionarios analizará la contribución de muchos de ellos en la construcción del imaginario del continente, por eso esta novela nos describe la personalidad de algunos de los que fueron contemporáneos de Simón Rodríguez.

1 Para Uslar toda novela era histórica.

"El campo de la novela es el tiempo, pero no la época, sino la acción del pasado en el presente y la transformación continua del presente en pasado a través del personaje, sus relaciones y sus fantasmas.

Es en este sentido que toda la novela es histórica por naturaleza, porque es una tentativa de contener un tiempo y de mantenerlo vivo en términos de presente, aunque la acción que se relate haya ocurrido muchos siglos antes." (Uslar, 2002, p. 886) 
REVISTA DE LA SEECI.

Febres-Cordero, Laura (2009): EL huidizo sentido de la independencia en la isla de Róbinson de Arturo Pietri. No 19. Julio. Año XIII. Páginas: 58 - 77

ISSN: 1576-3420 DOI: http://dx.doi.org/10.15198/seeci.2009.19.58-77

Muchos de ellos comparten ese terreno movedizo que limita con la locura, como es el caso de Fray Servando Teresa Mier quien afirmaba que "El evangelio fue predicado en América al mismo tiempo que en el resto de los otros continentes. Desde el siglo I de la Era Cristiana por Santo Tomás-Quetzalcoatl'. (Uslar, 1981, pág. 37) También nuestro imaginario participa de la visión del indio que tenía René de Chateaubriand en Atala o los amores de dos salvajes que Simón Rodríguez traduce del francés. "Había que ser un francés, como aquel fino y modulado hablar, para haber podido tener aquella visión del indio. Nunca los habíamos visto así Servando."

Basta esta pequeña frase para analizar el juego que establece el autor entre el estilo directo e indirecto en la novela. Las pinturas del narrador aparecen en estilo indirecto, mientras que las frases de los personajes tomadas de otros textos, aparecen entre comillas. Así el narrador nos introduce a través de estas señales gráficas dentro de su juego temporal que pretende darnos la sensación de un mundo con tiempos diferentes. No es lo mismo el tiempo lento de la Colonia caraqueña que el tiempo rápido de la República norteamericana, ni estos se parecían al tiempo en el París Postrevolucionario. Ni tampoco sería el mismo que nos dibuja cuando la balsa conduce a Simón Rodríguez hacia su morada definitiva. "La velocidad y la densidad del tiempo habían ido cambiando a su alrededor." (Uslar, 1981, pág. 44)

Para esta novela Arturo Uslar Pietri escoge como nudo principal de la trama el momento en que la Revolución de Independencia escapa a los límites de un solo territorio para convertirse en un suceso Latinoamericano y mundial. Las Lanzas Coloradas, primera novela de Arturo Uslar Pietri describe los inicios de este proceso en el territorio venezolano. 
REVISTA DE LA SEECI.

Febres-Cordero, Laura (2009): EL huidizo sentido de la independencia en la isla de Róbinson de Arturo Pietri. No 19. Julio. Año XIII. Páginas: 58 - 77

ISSN: 1576-3420 DOI: http://dx.doi.org/10.15198/seeci.2009.19.58-77

En Las lanzas coloradas, de la Independencia sólo se escoge la primera parte de su suceder, los años que van de finales del siglo XVIII cuando era Capitán General Manuel Guevara y Vasconcelos hasta 1814, año de la batalla de la Victoria. El período colonial de cierta paz que en ella se narra es muy pequeño, pero nos da a entender que la riqueza agrícola y cierto desarrollo cultural alcanzado en ese período van a ser

destruidos por la guerra que comienza. Pensamos, entonces, que la guerra es el personaje principal de esta primera novela. (Febres, 2001, pág. 258)

Sin embargo, la guerra no tiene ningún sentido en sí misma y es en La isla de Róbinson, donde Arturo Uslar Pietri intenta recuperar el significado, planteándonos también la interrogante de si es posible conferirle significado a los hechos humanos. Probablemente lo logramos con el lápiz pero será posible conseguirlo en la realidad.

La isla de Róbinson se desenvuelve como una novela histórica donde la noción de historia es problematizada, porque a ratos es escrita por un loco. En ella la historia, definida como aquella que confiere la explicación a los hechos humanos realizados en el pasado, es cuestionada. Sería más auténtico escribir una novela picaresca de la Independencia y no su historia:

“¿Todavía me tiene usted por loco? Antonio José de Irisarri negó con azoramiento y vehemencia."

"Esto no está para escribir historia. Don Antonio José, sino más bien para hacer una novela picaresca increíble. Todos los Rinconetes, los Lazarillos, los Guzmanes, los Pablos, se quedarían chiquitos. Hágala usted." (Uslar, 1981, pág. 325) 
REVISTA DE LA SEECI.

Febres-Cordero, Laura (2009): EL huidizo sentido de la independencia en la isla de Róbinson de Arturo Pietri. No 19. Julio. Año XIII. Páginas: 58 - 77

ISSN: 1576-3420 DOI: http://dx.doi.org/10.15198/seeci.2009.19.58-77

La revolución de Independencia, como la mayoría de las revoluciones, no produjo un cambio en la vida del hombre: "Cambian el gobierno pero no cambian las costumbres. Ése es el error de las revoluciones. Cambian las leyes pero no tocan la escuela. Tiempo perdido." (Uslar, 1981, pág. 73) Fue una guerra sumamente compleja, y a través de su estudio podemos acercarnos a lo que verdaderamente somos y seremos como pueblo.

Sentía que en el impulso destructor y creador de la Guerra de Independencia se había revelado de un modo pleno la condición criolla de nuestra humanidad.

"Fue el primer momento en que el alma criolla pudo entregarse con fruición posesiva a la irrestricta expresión de su ser. [...] La novela es para él maestra de la vida, y su condición imaginaria no invalida su mensaje de comprensión y acercamiento al proceso social de un pueblo". (Castro, 2002, pág. 632)

No solamente en la Guerra de Independencia hubo un afán destructivo y sacrificial, como el que observamos en Las Lanzas Coloradas, sino que observamos un intento constructivo como el de Simón Rodríguez. Por eso, la historia narrada en esta novela no va a tratar sólo del pasado sino también del tiempo futuro: "Lo que ha pasado no se puede borrar. Lo que hay que preparar es el futuro. Pero un futuro que pueda pertenecer a esas gentes." (Uslar, 1981, pág.70). Para Alexis Márquez Rodríguez el tiempo futuro forma parte estructural de la novela, el narrador de ella tiene el don de "recordar el porvenir, que no otra cosa sería la capacidad de adivinar el futuro". (Márquez, 1986, pág. 46)

De la misma forma como se cuestiona la historia y sus conceptos, los de revolución e Independencia, también se cuestiona la política: "Podríamos debatir sobre matemáticas 
REVISTA DE LA SEECI.

Febres-Cordero, Laura (2009): EL huidizo sentido de la independencia en la isla de Róbinson de Arturo Pietri. No 19. Julio. Año XIII. Páginas: 58 - 77

ISSN: 1576-3420 DOI: http://dx.doi.org/10.15198/seeci.2009.19.58-77

o sobre química, que son ciencias verdaderas, pero no sobre política". (Uslar, 1981, pág. 326)

A pesar del cuestionamiento que la novela hace del sentido de las cosas, en los baúles de Simón Rodríguez después de su muerte es lo único que queda. Ese sentido de la Independencia nos lo confieren las voces de sus más importantes personajes citados en la novela. No la de sus personajes pequeños, como los picaros, que ni siquiera la entienden. La voz principal sería la de Simón Rodríguez, su más importante ideólogo, por la comprensión americana que tiene del fenómeno: "Si él no había venido para buscar puestos o prebendas sino para realizar la obra gigantesca de hacer a América de nuevo y darle sentido completo a la Independencia". (Uslar, 1981, pág. 165)

También la de Simón Bolívar criticada por muchos personajes en el transcurso de la novela: "Gual tenía una visión clara y razonada de la situación. El libertador ve demasiado en grande. De allí el problema". (Uslar, 1981, pág. 160)

Además de la visión de Antonio J osé de Sucre:

Le confió que la Asamblea le iba a pedir que redactara el proyecto de constitución para el nuevo Estado. "Ya tenemos la experiencia de todos estos años y deberíamos conocer las fallas y los errores de los sistemas constitucionales que hemos ensayado. Vamos a proponer instituciones que no sean meras copias, sino respuestas directas a nuestras necesidades y características". (Uslar, 1981, pág. 228)

Pero es la primera voz, la que prevalece, la de Simón Rodríguez o Samuel Róbinson, porque se esfuerza en pintar sus ideas que inmediatamente muestran su contradictoria concreción: "Tiene usted razón, soy contradictorio. Yo he querido hacer de la tierra un 
REVISTA DE LA SEECI.

Febres-Cordero, Laura (2009): EL huidizo sentido de la independencia en la isla de Róbinson de Arturo Pietri. No 19. Julio. Año XIII. Páginas: 58 - 77

ISSN: 1576-3420 DOI: http://dx.doi.org/10.15198/seeci.2009.19.58-77

paraíso para todos, la convierto en un infierno para mí. Pero ¿qué quiere usted? La libertad me es más querida que el bienestar". (Uslar, 1981, pág. 298)

La libertad no es la única idea que puede hacer feliz al hombre. Sin embargo, por ella se sacrifican todos los demás anhelos que tiene la sociedad americana. Por lo tanto el resultado de la contienda no será, según Simón Rodríguez, definitivo; si no se educan otras virtudes ciudadanas. Con respecto a esto la novela está llena de los más sabios pensamientos, tomados por el autor directamente de los textos de Simón Rodríguez, utilizando el recurso de la intertextualidad y el estilo directo que recuerda sus ideas:

"Esta Independencia que hemos proclamado no es sino un armisticio, una suspensión de armas. Hay que hacer pueblo, hacer dirigentes, formar republicanos sobre una herencia de despotismo y monarquía. Cómo puede ejercer soberanía el pueblo si no lo hemos preparado. Este soberano ni aprendió a mandar, ni manda y el que manda a su nombre lo gobernará y lo esclavizará." (Uslar, 1981, pág. 198)

Uno de los ideales más queridos para el maestro Simón Rodríguez es crear un cuerpo social donde cada uno de los individuos concientizara su papel dentro de él: "LoS hombres viven juntos, Peña, pero carecen de la idea fundamental de la asociación que es pensar cada uno en todos para que todos piensen en él. Eso no lo enseñaba nadie. [...] Por eso viven todos contra todos y no hay sociedad". (Uslar, 1981, pág. 162)

Además de las virtudes ciudadanas, Simón Rodríguez le concede un papel muy importante a la productividad en la sociedad americana, que debe ser lograda a través de la educación y el trabajo: "Enseñen y tendrán quien sepa, eduquen y tendrán quien 
REVISTA DE LA SEECI.

Febres-Cordero, Laura (2009): EL huidizo sentido de la independencia en la isla de Róbinson de Arturo Pietri. No 19. Julio. Año XIII. Páginas: 58 - 77

ISSN: 1576-3420 DOI: http://dx.doi.org/10.15198/seeci.2009.19.58-77

haga. Enseñar a trabajar, a vivir en sociedad, a producir". (Uslar, 1981, pág. 198) "El hombre no es ignorante porque es pobre, sino al contrario". (Uslar, 1981, pág. 206)

No sólo hablaba de la educación del hombre en la sociedad, sino de la del hombre individual, como persona, al que se le habían aplicado normas que lo habían prostituido:

"Si no se cambia al hombre nada se cambia. Hay que tomarlo tierno y fresco. Sin nada todavía en la cabeza. ...Es por la cabeza por donde se le hace, o por donde se le permite encontrarse a sí mismo. Hablaba de sus ensayos en las Escuelas de Caracas y de lo que había visto en Francia. ...Más daño hace un abuelo imbécil hablando a su nietecito, que todo el bien que pueda procurarle a éste la escuela más avanzada. Lo que vuelve a aparecer en el niño es el viejo hombre con sus mismas sinrazones, sus miserables malos hábitos de pensamiento, sus rancias ideas y normas". (Uslar, 1981, pág. 54).

Consideramos que para analizar el fenómeno de la Independencia a fondo hacen falta otras voces con sentido en la novela. La voz de las mujeres que acompañaron a Rodríguez en su largo periplo por América. Ellas no hablan en estilo directo, solamente aparecen trasmitidas por el narrador. No habla la francesa, sin nombre, que muere contaminada por las aguas del Río Magdalena; tampoco habla Manuela Gómez, la indígena, madre de su hijo Cocho, quien acompaña a Simón Rodríguez en la balsa que lo conduce hasta el pueblo en donde morirá.

No deja el narrador de afirmarnos que ellas le hacen la vida más grata al personaje, pero no contribuyen en la empresa de darle sentido a la Independencia y mucho menos a cuestionarla. "Si no hubiera sido por esas pobres mujeres aniñadas y trabajadoras, 
REVISTA DE LA SEECI.

Febres-Cordero, Laura (2009): EL huidizo sentido de la independencia en la isla de Róbinson de Arturo Pietri. No 19. Julio. Año XIII. Páginas: 58 - 77

ISSN: 1576-3420 DOI: http://dx.doi.org/10.15198/seeci.2009.19.58-77

hubiera sido mucho peor su vida". (Uslar, 1981, pág. 177) Otra de ellas, sin nombre ni individualidad ninguna, sí habla. No sabemos qué dice. Con ella mantiene una relación sexual y es comparada con la tierra y se relata su habla con el mismo lenguaje de la tierra. "¿Qué dice su merced? Voy a entrar en la tierra". (Uslar, 1981, pág. 155)

Pero no sólo es falta de voz e individualidad, sino que las mujeres citadas no comprenden el pensamiento de Simón Rodríguez y mucho menos son capaces de compartirlo:

"¿Cómo le iba a explicar a ella que pensaba marcharse para aquella tierra perdida en el fondo del mundo llena de guerras, indios, monos y loros?

Parecía que iban juntos por la calle pero se perdían en la más completa separación de pensamientos e imaginaciones". (Uslar, 1981, pág. 146)

En el caso de las mujeres que acompañan a Simón Bolívar en su periplo La señora Tristán, Teresa Laisnay sólo dice: "Ven"- le dijo Teresa a Bolívar. Lo llevó a la alcoba. En una cuna de madera oscura dormía una niña de pocos meses. "¿Es?" "Es mi hija."Bolívar la vio con sorpresa y le pasó con suavidad la mano por la cara. "Se llama Flora." (Uslar, 1981, pág. 52) Es todo lo que dice ella en estilo directo.

Algo más fluido es el diálogo de Manuelita Sanz que para mostrarlo acude al estilo directo nuevamente:

"Estos mojigatos de Lima le han hecho ver que es escandaloso que yo me muestre en su casa. Que debemos vencernos nosotros mismos. Ha visto usted, señor Rodríguez, mayor disparate. Que ya 
REVISTA DE LA SEECI.

Febres-Cordero, Laura (2009): EL huidizo sentido de la independencia en la isla de Róbinson de Arturo Pietri. No 19. Julio. Año XIII. Páginas: 58 - 77

ISSN: 1576-3420 DOI: http://dx.doi.org/10.15198/seeci.2009.19.58-77

no podemos unirnos legalmente ante los hombres debemos hacer el sacrificio de separarnos. ¡Qué gracioso! ¡Qué fácil! Él seguirá para el Sur donde no le faltarán toda clase de descocadas, zorras, tías, busconas, gamberras. Allá se las halla. Y que yo me vuelva, como chica regañada, a la casa del inglés. No señor, no y mil veces no". (Uslar, 1981, pág. 196)

El sentido de la Independencia no es entendido en la novela por la mayoría de los latinoamericanos, por lo menos por la mitad de ellos, las mujeres, según el narrador, para las que utiliza siempre el estilo indirecto. Por eso, este se volverá tal vez un contrasentido que estudiaremos más a fondo en el siguiente punto de nuestro trabajo, cuando nos enfrentemos al monstruo que aparece en los libros de viajes.

\section{El libro de viajes}

Dejaríamos incompleto el estudio de esta novela si solamente la viéramos como una novela histórica sobre la Independencia y no hiciéramos conexión con todo el trasfondo de la literatura de viaje, que ya su mismo título enuncia: La isla de Róbinson, que nos recuerda las peripecias de Róbinson Crusoe. En esta isla el personaje se siente frecuentemente solo, por eso busca la compañía silente de las mujeres, de fray Fray Servando Teresa Mier, de Simón Bolívar, de sus alumnos y de su último discípulo Camilo Gómez quien lo acompaña a la hora de su muerte. Pero esta compañía transitoria nunca es definitiva. Samuel Róbinson vuelve a estar solo en su isla, una y otra vez.

El personaje principal ha leído la historia que esta novela parodia: "Más tarde, cuando leyó la historia de Róbinson Crusoe, se dio cuenta de que él también, a su manera, 
REVISTA DE LA SEECI.

Febres-Cordero, Laura (2009): EL huidizo sentido de la independencia en la isla de Róbinson de Arturo Pietri. No 19. Julio. Año XIII. Páginas: 58 - 77

ISSN: 1576-3420 DOI: http://dx.doi.org/10.15198/seeci.2009.19.58-77

había sido un náufrago aventado en una isla. Una isla grande y desconocida". (Uslar, 1981, pág. 22)

América, esta isla que él intenta conocer se le resiste. No logra abarcarla en sus continuos viajes y mucho menos dominar sus recursos fundamentales. Róbinson, el naufrago por antonomasia que desde niños conocimos, se convierte en el viajero Simón Rodríguez o Samuel Róbinson, el gran ideólogo de de la Independencia, que viene definida en el libro como una gran tormenta. "Soy un náufrago. Un naufrago del mar, o casi, y uno ciertamente de la vida. Hasta aquí me ha traído la tormenta". (Uslar, 1981, pág. 186)

La mayoría de los personajes son arrojados por esta tormenta fuera de su tierra nativa. Hay párrafos en la novela que recuerdan los libros de viaje donde le océano juega un papel fundamental: "Cuando se descolgaban desmayadas de viento las velas a lo largo de la arboladura, a mecerse por horas y días en una calma de estaño azul, en mitad del océano". (Uslar, 1981, pág. 150)

Y en ese océano, como en el primer libro de viajes La Odisea, está el monstruo que espera aniquilar al viajero. Este monstruo también actúa en tierra y representa la forma en que se destruye al personaje principal:

"Fue con esas garras y con esas fauces, disimuladas, escondidas, untuosas, con las que lo atraparon y lo destruyeron. Todo 10 cambiaban, lo adulteraban, lo fingían. El venía a buscar a Bolívar y se lo habían escamoteado. Él quería organizar una república y lo que brotaba a su espalda, como retoño de mala hierba tenaz, era la vieja mentira, el orden vetusto de salas, patios y corrales, el mi amo de la 
REVISTA DE LA SEECI.

Febres-Cordero, Laura (2009): EL huidizo sentido de la independencia en la isla de Róbinson de Arturo Pietri. No 19. Julio. Año XIII. Páginas: 58 - 77

ISSN: 1576-3420 DOI: http://dx.doi.org/10.15198/seeci.2009.19.58-77

indiada, el orgullo de los señores de nada. Él sembraba una escuela y que brotaba era un hospicio de mendigos". (Uslar, 1981, p. 152)

La realidad que él quería crear, se convierte en otra cosa. La realidad se le resiste. Pareciera que la ley de la causalidad funcionara al revés y todo lo previsto se transformara en su antítesis. Frente a esto lo único seguro era el viaje, lo transitorio y sin raíces. Esto es lo único verdadero.

De esta manera la Independencia se convierte, para Simón Rodríguez en un viaje interminable que acaba con su muerte. Episodios como su huída de Caracas a París, por su complicidad en la revuelta de Gual y España. Luego su viaje por este continente con el que luego será uno de los grandes libertadores de América, Simón Bolívar; a quien concientiza de la importancia de su misión y ayuda a planificar su actividad futura en episodios como el de Monte Sacro. Su regreso a América para acompañar al Libertador en su misión. La separación de ambos. Su estadía en Arequipa donde imprimirá parte de sus obras. Su viaje a Chile intentando hacer realidad sus ideas científicas. Y su muerte en la absoluta soledad, sólo acompañado por un discípulo Camilo Gómez, en la cercanía de un pequeño pueblo, Amotape en Perú. Son algunos episodios que no nos dejan ninguna duda de que la novela participa abiertamente de la estructura de la novela de viajes que el autor ya señala en su título y termina con la muerte del personaje: "Róbinson había dejado la isla". (Uslar, 1981, pág. 357) 


\section{La escritura en La Isla de Róbinson}

Sin embargo, el libro de viajes y la novela histórica se van escribiendo consecutivamente, sin dejar de reflexionar acerca del proceso de construcción de este libro, que es la creación novelística de la Isla de Róbinson, pintada sólo con el lápiz.

En la novela las citas a autores, títulos y párrafos de libros, y periódicos son tantas, que ellas mismas van construyendo la obra. En ella, la mayoría de sus personajes, no sólo cuentan la realización de sus hazañas sino que también las leen y las escriben.

"Salió lentamente y de espaldas. Bolívar continuaba dictando. Escribía al General Briceño Méndez, al Licenciado Revenga, al coronel Diego Ibarra. Cambiaba de tono y cambiaba el invisible interlocutor". (Uslar, 1981, pág. 222)

De la misma forma escribe Antonio José de Sucre su experiencia con Simón Rodríguez alias Samuel Róbinson, el maestro del Libertador:

"Al describir a Ud. todas las locuras de este caballero tendría que ser muy largo. Ud. pensará que yo estoy muy enfadado con él y no es así. Considero a Don Samuel un hombre muy instruido, benéfico cual nadie, desinteresado hasta lo sumo y bueno por carácter y por sistema; pero lo considero también una cabeza alborotada con ideas extravagantes, y con incapacidad para desempeñar el puesto que tiene bajo el plan que él dice y que yo no sé cuál es; porque diferentes veces le he pedido que me traiga por escrito el sistema 
REVISTA DE LA SEECI.

Febres-Cordero, Laura (2009): EL huidizo sentido de la independencia en la isla de Róbinson de Arturo Pietri. No 19. Julio. Año XIII. Páginas: 58 - 77

ISSN: 1576-3420 DOI: http://dx.doi.org/10.15198/seeci.2009.19.58-77

que él quiere adoptar para que sirva de regla y en ocho meses no me lo ha podido presentar". (Uslar, 1981, pág. 234)

El personaje principal escribe durante la trayectoria novelística varios libros y muchas cartas de las cuales la novela cita constantemente fragmentos. Pero su grafía no era uniforme, sino que intentaba no sólo impresionar con lo que se contaba sino con la forma como éste material estaba escrito.

No era nada escribir en el rincón del cuarto pobre donde se acodaba por horas, abstraído de todo. Lo peor era la disputa continua con el impresor.

"¿Qué necesidad hay de ser tantos tipos distintos de letras de todos tamaños? La gente se va a confundir. No se preocupe usted. Ya aprenderán. Escribir es pintar ideas. Lo que yo trato es de pintarlas con más claridad. ¿Cómo sabe uno donde está lo importante en esas páginas grises y parejas de los libros ordinarios?". (Uslar, 1981, pág. 260)

Existen una gran cantidad de referencias en la novela de que la Independencia se creará y también se aniquilará a través del lenguaje. Su autor y su personaje principal están escribiendo ambos varios libros:

Se llamaría "El libertador del Mediodía de América y sus compañeros de armas defendidos por un amigo de la causa social' (Uslar, 1981, pág.253). Sin embargo, como todo en esta novela termina cambiando su esencia, este libro también la varía "ya no era un libro, a pesar de que se acumulaban por centenares los pliegos sobre su mesa, 
REVISTA DE LA SEECI.

Febres-Cordero, Laura (2009): EL huidizo sentido de la independencia en la isla de Róbinson de Arturo Pietri. No 19. Julio. Año XIII. Páginas: 58 - 77

ISSN: 1576-3420 DOI: http://dx.doi.org/10.15198/seeci.2009.19.58-77

sino un diálogo iracundo con todos los que no querían oír ni entender." (Uslar, 1981, pág. 254)

Para Simón Rodríguez la Independencia tenía un sentido que muchos no querían o no podían entender. Sólo la comprenden sus grandes voces. Por eso se dedica a través de sus escritos a conferirle ese sentido que no es claro para todos. Pero de esa búsqueda sólo nos queda aquella "caja de papeles", "aquel eco de lo más viviente de todo lo que él había vivido" (Uslar, 1981, pág. 183) que intenta Uslar Pietri recrear con su pincel en la novela.

\section{Bibliografia}

DELPRART, F. Coordinador. (2002) Arturo Uslar Pietri. Las Lanzas coloradas. Primera narrativa. ALLCA XX. Madrid; Barcelona; La Habana; Lisboa; París; México; Buenos Aires; São Paulo; Lima; Guatemala; San J osé; Caracas.

FEBRES, L. (Compiladora) (2006) A los amigos invisibles Visiones de Arturo Uslar Pietri. Universidad Metropolitana. Caracas.

GARCIA, M; MORENO, J; ARRAIZ LUCCA, R; LOSADA, B; PAIVA REINOSO, A; STAMBOULI, A; AVELEDO, R; GUÉDEZ, V; VILORIA VERA, E; FEBRES, L. KRISPIN, K. (2001) Todo Uslar. Universidad Metropolitana. Caracas.

MARQUEZ RODRIGUEZ, Alexis. (1986) Arturo Uslar Pietri y la nueva novela histórica. Contraloría General de la República. Caracas.

RODRIGUEZ, S. (1990) Sociedades americanas. Biblioteca Ayacucho, versión digital. Caracas. 
REVISTA DE LA SEECI.

Febres-Cordero, Laura (2009): EL huidizo sentido de la independencia en la isla de Róbinson de Arturo Pietri. No 19. Julio. Año XIII. Páginas: 58 - 77

ISSN: 1576-3420 DOI: http://dx.doi.org/10.15198/seeci.2009.19.58-77

USLAR PIETRI, Arturo. (1981) La isla de Róbinson. Editorial Seix Barral, S.A. Barcelona, Caracas, México.

USLAR PIETRI, Arturo. (1975). El globo de colores. Monte Ávila. Caracas.

USLAR PIETRI, Arturo. (1979). Las Lanzas Coloradas. Biblioteca Ayacucho. Caracas.

USLAR PIETRI, Arturo. (1990). La vista en el tiempo. Editorial Norma. Bogotá.

USLAR PIETRI, Arturo. (1986). Godos, insurgentes y visionarios. Seix Barral, S.A. Barcelona.

USLAR PIETRI, Arturo. (1987). Giotto y compañía. Fundación Mendoza. Caracas. 